\title{
Engaging Students with Profound and Multiple Disabilities Using Humanoid Robots
}

\author{
Penny Standen ${ }^{1}$, David Brown ${ }^{2}$, Jess Roscoe ${ }^{1}$, Joseph Hedgecock ${ }^{1}$, David \\ Stewart $^{3}$, Maria Jose Galvez Trigo ${ }^{2}$, and Elmunir Elgajiji ${ }^{2}$ \\ 1 University of Nottingham, Nottingham, UK \\ \{p.standen,mzyjr,mzyjh1\} @nottingham.ac.uk \\ 2 Nottingham Trent University, Nottingham, UK \\ david.brown@ntu.ac.uk, \\ \{maria.trigo2013,elmunir.elgajiji2012\}@my.ntu.ac.uk \\ 3 Oak Field School and Sports College, Nottingham, UK \\ d.stewart@oakfield.nottingham.sch.uk
}

\begin{abstract}
Engagement is the single best predictor of successful learning for children with intellectual disabilities yet achieving engagement with pupils who have profound or multiple disabilities (PMD) presents a challenge to educators. Robots have been used to engage children with autism but are they effective with pupils whose disabilities limit their ability to control other technology? Learning objectives were identified for eleven pupils with PMD and a humanoid robot was programmed to enable teachers to use it to help pupils achieve these objectives. These changes were evaluated with a series of eleven case studies where teacherpupil dyads were observed during four planned video recorded sessions. Engagement was rated in a classroom setting and during the last session with the robot. Video recordings were analysed for duration of engagement and teacher assistance and number of goals achieved. Rated engagement was significantly higher with the robot than in the classroom. Observations of engagement, assistance and goal achievement remained at the same level throughout the sessions suggesting no reduction in the novelty factor.
\end{abstract}

Keywords: Robots, education, engagement, profound and multiple intellectual disabilities, case studies, video analysis.

\section{Introduction}

Intellectual disabilities are estimated to affect between 1 and $2 \%$ of the population in most western countries and currently $20 \%$ of the population with intellectual disabilities will be of school age. Although the number who are of school age is remaining stable [1] there has been a large rise in the number of children with profound and multiple disabilities (PMLD). This has been attributed to an increase in the survival of premature babies due to medical advances made in recent years [2]. These children often have the most complex needs, due to a combination of extremely delayed intellectual and social functioning, no verbal communication and the presence of 
associated medical conditions usually neurological, sensory or physical impairments [3]. This makes it almost impossible for them to benefit from available educational provision and new ways are needed to foster their learning. According to Iovannone et al. [4] engagement is "the single best predictor" of learning for children with intellectual disabilities. Discussing children with complex needs, Carpenter [5] writes that "Sustainable learning can occur only when there is meaningful engagement. The process of engagement is a journey which connects a child and their environment (including people, ideas, materials and concepts) to enable learning and achievement" (p35). Can computer technology help to foster engagement in these learners?

Most educational interventions using computer technology have been designed for the more able. A recent systematic review [6] on the use of iPods, iPod Touch and iPads in teaching programs for people with developmental disabilities noted an absence of studies on individuals with profound and multiple disabilities. They concluded that this group presents unique challenges with respect to the design of technology-based interventions, a major one being their lack of sufficient motor control to activate the device and software.

There have been some attempts to circumvent this problem of motor control. Work by Lancioni [7] has demonstrated there is a way for almost anyone to activate a microswitch, the most common being a push switch, which is activated by applying pressure to a large button. However they can also be triggered by pressure sensors on the armrest of a wheelchair, by chin or eyelid movement [8] or by vocalisation [9]. This then allows the user to exert environmental control, activate a piece of equipment which may produce speech on their behalf, or begin a pleasurable stimulus for the user.

There have also been attempts to capture gesture or body movements using infrared sensor-based systems to enable those with multiple disabilities to control multimedia [10]. A more recent development that can allow a profoundly disabled person to interact with their environment has been enabled by the appearance of low cost headsets that enable gamers to interact with games using their own brain activity [11].

Work with typically developing children has shown that robots can help attainment in a wide range of areas, particularly by motivating children [12,13]. A wide range of robots has already been used with children with disabilities [14], although the majority of these have focussed on children with autism [15]. Studies involving children with intellectual disabilities are promising but focus on those who are more able. Klein et al. [16] showed that working with a robot increased "playfulness" and therefore engagement in two out of the three young children with developmental disabilities in their study. Introducing a mobile robotic platform to eight children with either autism, Downs syndrome or severe learning disabilities showed high levels of motivation and engagement in all the children [17].

As a preliminary step to investigate the suitability of robots for profound and multiply disabled school aged children, Hedgecock [18] interviewed teachers of children with intellectual disabilities to discover their opinions of using a NAO humanoid robot as an educational tool, which children they believed would benefit, what learning aims they would target, and what methods they would suggest to achieve them. Information derived from the interviews was then used to design a series of five case studies to evaluate potential teaching methods and outcome measures. For example, in one case study a nine year old boy with severe intellectual disabilities and reduced vision learnt that by clapping his hands he could get the robot to perform a dance. 
However, he had problems with perseveration so the aim of the sessions was to help him learn to perform the action only once and to stop when the robot did what he wanted. The case studies were video recorded and recordings analysed to measure engagement, teacher assistance and goal achievement. A questionnaire completed by the pupils' teachers was also used to compare engagement in class to engagement within the final session. Analysis of the interviews highlighted the importance of having an appropriate input device to make the robot accessible, for example by making it sensitive to vocalisations, gestures or switch operations: whatever was favoured by the child. Teachers also emphasised the importance of "productive learning" ie that leads to being able to achieve something important for the pupil rather than being seen as just play and of designing sessions tailored to individuals' needs and interests. In the case studies, pupils showed significantly higher engagement when working with a robot when compared to not working with a robot.

The teachers in this study came up with many more possible uses for the robot than it could perform. This indicated a need for the robot to be able to perform a greater range of actions as a reward or cue that could be personalised for individual students. What the study also showed was that the robot needed a greater range of ways to be controlled to enable a wider range of pupils to use it. The aims of the present study were:

1. To produce adjustments to the robot's programming in order to

a. make it controllable by other input devices (eg switches, joystick)

b. enable it to emit a greater range of behaviours (eg different dances, tunes etc)

2. To evaluate the new repertoire with a series of case studies.

\section{Methods}

\subsection{Design}

Changes to the robot's programming were informed by results from the previous study [18] and from discussions with teachers. Changes were evaluated using a series of single case studies where teacher-pupil dyads were observed during four planned video recorded sessions with a robot. Engagement was rated in a classroom setting and during the last session with the robot.

\subsection{Participants}

Eight members of teaching staff (six teachers and two teaching assistants) from a school in Nottingham with around 150 pupils with severe, profound or complex learning and/or physical disabilities nominated one or two pupils to work with. Four teachers nominated two pupils. There were no exclusion criteria for the pupils other than parents not consenting. The characteristics of the pupils are shown in Table 1. 
Table 1. Characteristics of participants

\begin{tabular}{|c|c|c|c|}
\hline Pupil & $\begin{array}{c}\text { Gender } \\
\text { age (years) }\end{array}$ & Details of disability & $\begin{array}{l}\text { Attainment le- } \\
\text { vels }\end{array}$ \\
\hline $\mathrm{S} 1$ & Male, 17 & $\begin{array}{l}\text { S1 has complex intellectual disabilities, epi- } \\
\text { lepsy and global developmental delay. He has } \\
\text { fine and gross motor development difficulties, } \\
\text { limited speech and no awareness of danger. }\end{array}$ & NC1, NC1, C1. \\
\hline $\mathrm{S} 2$ & Female 12 & $\begin{array}{l}\text { S2 has dyskinetic cerebral palsy resulting in } \\
\text { mobility difficulties, varying muscle strength } \\
\text { and involuntary movements. S2 also strug- } \\
\text { gles substantially with language and com- } \\
\text { munication. }\end{array}$ & P7, P7, P8 \\
\hline S3 & Male 7 & $\begin{array}{l}\text { S3 suffers from Duchene Muscular Dystro- } \\
\text { phy and an Autistic Spectrum Disorder. He } \\
\text { struggles to understand spoken language, is } \\
\text { wary of unfamiliar environments and has } \\
\text { difficulties with learning, communication } \\
\text { and social interaction. }\end{array}$ & $\mathrm{P} 1, \mathrm{P} 1, \mathrm{P} 1$ \\
\hline S4 & Male 5 & $\begin{array}{l}\text { S4 suffers from Down's syndrome. He has } \\
\text { learning, language, social interaction and } \\
\text { behavioural difficulties. S4 also has violent } \\
\text { tendencies and a preference for solitary play. }\end{array}$ & P3, P3, P3 \\
\hline S5 & Male 18 & $\begin{array}{l}\text { S5 has cerebral palsy due to oxygen depriva- } \\
\text { tion at birth. He suffers from severe physical } \\
\text { and medical difficulties including learning } \\
\text { and communication challenges. With low } \\
\text { muscle tone and poor control of his trunk } \\
\text { and limbs, S5 is either wheelchair or walker } \\
\text { bound at all times. }\end{array}$ & $\mathrm{NC} 2, \mathrm{NC} 2, \mathrm{P} 8$ \\
\hline S6 & Female 20 & $\begin{array}{l}\text { S6 has cerebral palsy and severe intellectual } \\
\text { disabilities. Wheelchair bound with impaired } \\
\text { cognitive and communication skills due to } \\
\text { brain damage at birth. Home languages are } \\
\text { Romani and Polish }\end{array}$ & P6, P6, P4 \\
\hline S7 & Male 18 & $\begin{array}{l}\text { S7 has severe and multiple intellectual diffi- } \\
\text { culties with no known cause. S7 is nonverbal } \\
\text { and wheelchair or walker bound, showing } \\
\text { minimal communication abilities. }\end{array}$ & $\mathrm{P} 4, \mathrm{P} 4, \mathrm{P} 4$ \\
\hline S8 & Male 12 & $\begin{array}{l}\text { S8 suffers from cerebral palsy resulting in } \\
\text { spastic quadriparesis. As a result he suffers } \\
\text { from a mild delay in cognitive development } \\
\text { and speech and language deficits. S8 is } \\
\text { wheelchair bound, showing no evidence of } \\
\text { difficulties with attention or concentration. }\end{array}$ & $\mathrm{NC} 3, \mathrm{NC} 1, \mathrm{P} 8$ \\
\hline
\end{tabular}


Table 1. (continued)

\begin{tabular}{|l|l|l|c|}
\hline S10 & Male 11 & $\begin{array}{l}\text { S10 suffers from ATRX syndrome, resulting } \\
\text { in limited mobility, delayed learning and } \\
\text { minimal communication skills. S10 is tube } \\
\text { fed and suffers from recurrent chest infec- } \\
\text { tions and urinary tract infections. }\end{array}$ & P3, P3, P3 \\
\hline S11 & Male 11 & $\begin{array}{l}\text { S11 has an Autistic Spectrum Disorder with } \\
\text { severe intellectual disabilities and significant } \\
\text { hearing loss. Pr. He has microcephaly and } \\
\text { hypermetropia. S11 suffers from a short } \\
\text { attention span and has little understanding of } \\
\text { words relying instead upon verbal cues. }\end{array}$ & P2, P2 \\
\hline S12 & Male 7 & $\begin{array}{l}\text { S 12 has bilateral sensori-neural hearing } \\
\text { loss, congenital hypothyroidism, language } \\
\text { and communication difficulties and epilepsy. } \\
\text { As a result he has delayed self-help and } \\
\text { independent skills. }\end{array}$ & P6, P6, P5 \\
\hline
\end{tabular}

Attainment levels are given in the form of either National Curriculum levels (NC) or Performance Scales (P levels). P levels are a performance measure for children with Special Educational Needs, who do not meet the criteria for the lowest national curriculum level 1 [19]. P levels range from 1 to 8 with 1 being the lowest level of attainment. Pupils in the study are described in terms of their attainment levels for English, Maths and ICT.

\subsection{Intervention}

The robot used in this project was a NAO NextGen (Model H25, Version 4) humanoid robot, which is commercially available from robotics manufacturer Aldebaran Robotics. NAO is manufactured with a wide range of behaviours, including walking, standing up and sitting down, dancing, and recognising speech, sounds and objects as well as producing speech from text and playing sound files. These behaviours can all be programmed into the robot using Choregraphe [20], a user-friendly graphical interface that allows users to control the robot and create sequences of complex behaviours. Following the interviews with teaching staff in the previous study [18] and the collection of feedback from other staff at the school, changes were made to allow the control of the robot by Jellybean switches (see Figure 1) and a joystick thus allowing pupils to interact with the robot using a method suitable to their needs.

In order to allow a switch or joystick to control the robot, Pygame, a cross platform set of Python modules designed for writing video games was used. Pygame is built over a library that allows the use of a high-level programming language like Python in order to structure a program that could be used with several input devices. Next, a piece of Python code was written to produce a virtual server that could act as a bridge between the robot and any input device the pupil required such as Jellybean switches 


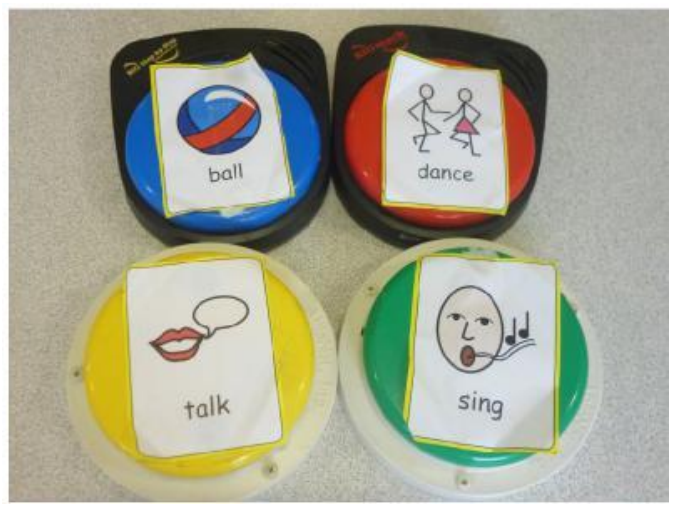

Fig. 1. Four Jellybean switches labelled with the symbols representing the microswitches' action

or a joystick. In this way, executing the program corresponding to the server and running the appropriate behaviour in Choregraphe it was possible to tele-operate the robot with different input devices.

There were three ways to increase the range of behaviours from those already offered by Choregraphe. First of all, there were some routines freely available for download from the internet. Secondly, favourite pieces of music could be transformed into .wav files and then included as a complete instruction in Choregraphe. Finally, more complex behaviours such as kicking a football, were first of all broken down into components for which script was written in Python and then included as a complete instruction in Choregraphe.

\subsection{Outcome Measures}

As in the previous study [18] engagement was rated using the scale developed by the Special Schools and Academies Trust [21] as part of a classroom tool for teachers of children with complex disabilities. The pupil is given a rating between 0 (no focus) and 4 (fully sustained) for each factor, giving a total score out of 28 , with a higher score indicating greater engagement. Video recordings of sessions were analysed to measure three variables: duration of pupil engagement, duration of assistance from staff, and the frequency of goals attained. These were converted to a percentage of the session to take account of the variation in session length.

\subsection{Procedure}

Teachers were recruited from those that attended a demonstration of the robot at the school given by the research team. In individual meetings with one of the authors (JR) they identified a pupil whom they thought would benefit from working with the robot. Once parental consent had been obtained, discussions were held with the teachers to devise an appropriate learning objective for the pupil to achieve in the sessions and 


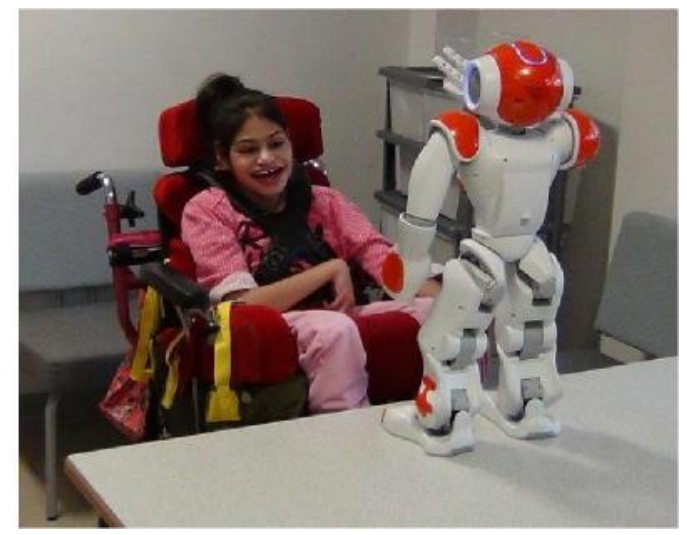

Fig. 2. A pupil working with the robot

discuss how this may be achieved. Information from these discussions was then used to individually design the sessions for each pupil, focussing on their interests and learning style, to help them achieve their learning objective. Figure 2 shows an example of how a pupil might be positioned to interact with the robot. Initial plans for the sessions were finalised with the teachers. However, depending on how sessions proceeded, plans could be refined. The main objective to be achieved over the four sessions could be broken down into smaller goals for each session.

Five sessions were conducted with each teacher-pupil dyad, all of which were digitally video recorded although the first session was intended to familiarise the pupil with the arrangements and to judge whether any adjustments to plans were required. Session length depended upon each child's ability to maintain focus, varying from seven to fifty minutes with a mean duration of twenty-two minutes. Sessions were scheduled at regular intervals over three weeks at times convenient to the teachers. Sessions were carried out in a room with just the pupil, researcher and a member of staff present.

The engagement scale [21] was completed by one of the authors (JR) in each pupil's normal classroom setting and again during each pupil's final session with the robot. Teachers attempted to follow similar learning objectives in the classroom as the ones they were planning for the session with the robot. Video recordings of each session were analysed by one of the authors (JR) using OBSWIN (http:// www.antam.co.uk/obswin.htm) for the duration of engagement, duration of assistance provided and the frequency of achieving a goal. Due to the inherent variability of the pupils, each pupil had individual criteria for the presence/absence of each variable. In order to determine what constitutes the presence/absence of a variable, videos of the sessions were watched before the analysis began, and exact criteria defined for each. 
Table 2. Learning objectives of sessions and robot actions

\begin{tabular}{|c|c|c|c|}
\hline & $\begin{array}{l}\text { Learning Objectiv } \\
\text { derived from inter } \\
\text { view with associated } \\
\text { staff member }\end{array}$ & $\begin{array}{l}\text { Behaviours programmed into ro- } \\
\text { bot that are specific to this student }\end{array}$ & $\begin{array}{l}\text { Input device(s) } \\
\text { used }\end{array}$ \\
\hline S1 & $\begin{array}{l}\text { To improve verba } \\
\text { communication. }\end{array}$ & $\begin{array}{l}\text { Robot will respond to voice com-I } \\
\text { mands from the student, if the stu- } \\
\text { dent is not clear enough NAO will } \\
\text { provide encouragement. }\end{array}$ & $\begin{array}{l}\text { Micro-switches, } \\
\text { voice input }\end{array}$ \\
\hline S2 & $\begin{array}{l}\text { To develop patience } \\
\text { and practice spelling }\end{array}$ & $\begin{array}{l}\text { Robot will respond to } \mathrm{S} 2 \text { if she } \\
\text { presses the micro-switch once only. } \\
\text { Robot will help S2 practice her spel- } \\
\text { ling using her hand-held computer to } \\
\text { vocalise words. If correct NAO will } \\
\text { reward S2 with a song or dance and } \\
\text { will encourage if incorrect. }\end{array}$ & $\begin{array}{l}\text { Micro-switches, } \\
\text { voice input } \\
\text {. }\end{array}$ \\
\hline S3 & $\begin{array}{l}\text { To learn cause anc } \\
\text { effect }\end{array}$ & $\begin{array}{l}\mathrm{d} \text { Robot will perform songs that } \mathrm{S} 3 \text { has } \\
\text { shown interest in if } \mathrm{S} 3 \text { correctly se- } \\
\text { lects the active switch. For additional } \\
\text { engagement, NAO will perform in } \\
\text { the dark lit up with many different } \\
\text { lights }\end{array}$ & Micro-switches \\
\hline S4 & $\begin{array}{l}\text { To practice } \\
\text { activation }\end{array}$ & $\begin{array}{l}\text { hRobot will verbally encourage } \mathrm{S} 4 \text { to } \\
\text { mimic him and warn him not to be } \\
\text { violent (as is his tendency) }\end{array}$ & Micro-switches \\
\hline S5 & $\begin{array}{l}\text { To improve verba } \\
\text { communication }\end{array}$ & $\begin{array}{l}\text { Robot will demonstrate one of S5's } \\
\text { physiotherapy exercises encouraging } \\
\text { her to touch her ear with her hand } \\
\text { prior to pressing the micro-switches }\end{array}$ & $\begin{array}{l}\text { Micro-switches, } \\
\text { voice input }\end{array}$ \\
\hline S6 & $\begin{array}{l}\text { To learn to obey com- } \\
\text { mands }\end{array}$ & $\begin{array}{l}\text { Robot will give verbal commands to } \\
\text { S6 asking him to pick up/throw/pass } \\
\text { a ball with encouragement }\end{array}$ & Voice input \\
\hline S7 & $\begin{array}{l}\text { To practice switcl } \\
\text { control with only one } \\
\text { hand }\end{array}$ & $\begin{array}{l}\text { hRobot will verbally encourage S7 to } \\
\text { use only one hand to trigger micro- } \\
\text { switches }\end{array}$ & Micro-switches \\
\hline S8 & $\begin{array}{l}\text { To develop confidence } \\
\text { in using a joysticl } \\
\text { similar to that of his } \\
\text { electric wheelchair }\end{array}$ & $\begin{array}{l}\text { Robot will move forwards, back- } \\
\text { kwards, left and right if S8 uses the } \\
\text { joystick effectively }\end{array}$ & Joystick \\
\hline
\end{tabular}


Table 2. (continued)

\begin{tabular}{|c|c|c|}
\hline S10 & \begin{tabular}{|l}
$\begin{array}{l}\text { To learn cause and } \\
\text { effect }\end{array}$ \\
$\qquad \begin{array}{l}\text { grammed with a wider range of } \\
\text { songs. One of NAOs switches will be } \\
\text { inactive for S10 to learn cause and } \\
\text { effect and not simply press random } \\
\text { switches }\end{array}$
\end{tabular} & -switches \\
\hline S11 & \begin{tabular}{|l|l|}
$\begin{array}{l}\text { To practice holding Robot will walk towards S11 once } \\
\text { objects for a long pe- } \\
\text { riod of time }\end{array}$ & $\begin{array}{l}\text { the switch is pressed and hand him an } \\
\text { object (initially food) to hold }\end{array}$ \\
\end{tabular} & $\begin{array}{l}\text { A single micro- } \\
\text { switch }\end{array}$ \\
\hline S12 & $\begin{array}{l}\text { verbal Robot will respond to voice com- } \\
\text { mands from the student, if the stu- } \\
\text { dent is not clear enough NAO will } \\
\text { provide encouragement as with S1 }\end{array}$ & Voice input \\
\hline
\end{tabular}

\section{$3 \quad$ Results}

Figure 3 summarises the group results for all outcome measures. Engagement scale results indicated that engagement with the robot (mean $=18.18, \mathrm{SD}=7.60)$ was

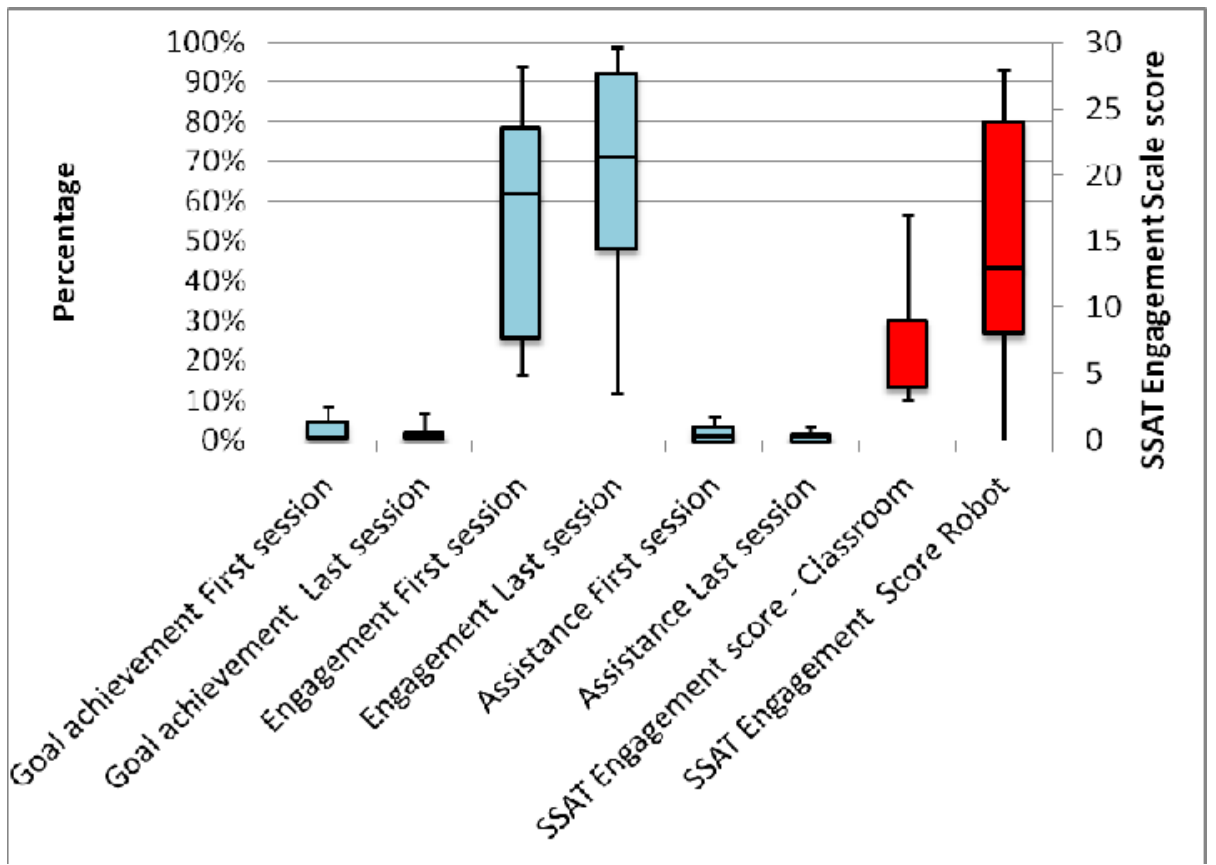

Fig. 3. Medians, quartiles and ranges for ratings of engagement and behaviours from video analysis 
significantly $(\mathrm{t}=4.9$, df $10, \mathrm{p}<0.001)$ higher than when in the classroom (mean = $8.64, \mathrm{SD}=4.11$ ). All but one of the pupils showed higher engagement when working with the robot: one received 28 points, the maximum score possible indicating full engagement throughout the entire session with the robot, compared with minimal engagement ( 9 points) in the classroom setting. Video analysis indicated that pupils were spending a high percentage of the time scored as showing engagement and although comparing scores from the first recorded session with those from the last session indicated an increase with time, this did not reach significance. Similarly, there was no significant change in either teacher assistance or goal attainment from first to last sessions

\section{Discussion}

The first aim of the study was to enable the robot to be controlled remotely by microswitches and a joystick and to enlarge its range of behaviours to allow it to support the learning of a wider range of pupils. This was successful to the extent that eleven pupils who varied considerably in ability, needs and interests had sessions with the robot tailored to their learning objectives. In evaluating these interventions, one of the hopes in using the robot was to improve pupil engagement given the importance of this quality in learning in pupils with intellectual disabilities. The higher ratings of engagement during the final session with the robot than in the classroom suggest that this was indeed the case. This is only a preliminary study and the rating scale results are potentially open to bias as it was not possible to carry them out without knowing which condition the pupil was in. Video analysis also showed high levels of engagement and these did not decline over time suggesting that the novelty factor of working with a robot had not waned at least for the duration of the study. Goals continued to be achieved at a steady level throughout suggesting that productive learning was taking place and this goal achievement did not require a great deal of teacher assistance.

While this might appear to be an expensive way of supporting learning, it was justified by one teacher in the earlier study [18] who commented that, for children with considerable physical disabilities, even maintaining their position requires considerable physical work. If you are then asking them to learn a new response, a considerably attractive reward is going to be necessary. For children who may spend the majority of their time in a wheelchair that they cannot move independently, active involvement in learning is very difficult for the teacher to engineer. In addition to providing an active element, this would also provide a sense of empowerment for individuals who have very little control over their surroundings.

\section{References}

1. Clarke, A.: Statistical First Release: Special Educational Needs in England, Department for Education, London (2012), http: //www. education.gov.uk/rsgateway/ $\mathrm{DB} / \mathrm{SFR} / \mathrm{s} 001075 / \mathrm{sfr} 14-2012 \mathrm{v} 2 . \mathrm{pdf}$ 
2. Salt, T.: Salt Review: Independent Review of Teacher Supply for Pupils with Severe, Profound and Multiple Learning Difficulties (SLD and PMLD) Ruddington (2010),

http://www.thedyslexia-spldtrust.org.uk/ media/downloads/inline/the-salt-review.1298547606.pdf

3. Bellamy, G., Croot, L., Bush, A., Berry, H., Smith, A.: A study to define: profound and multiple learning disabilities (PMLD). Journal of Intellectual Disabilities 14(3), 221-235 (2010)

4. Iovannone, R., Dunlap, G., Huber, H., Kincaid, D.: Effective Educational Practices for Students With Autism Spectrum Disorders. Focus on Autism and Other Developmental Disabilities 18(3), 150-165 (2003)

5. Carpenter, B.: Overview of the research project: steps and impact. Paper to the Complex Learning Difficulties and Disabilities Dissemination Conference. London (March 24, 2011), http: //complexld.ssatrust.org.uk/uploads/ SEN54\%20complex\%20needs.pdf

6. Kagohara, D., van der Meer, M., Ramdoss, L., O’Reilly, S., Lancioni, M.F., Davis, G.E., Rispoli, T.N., Lang, M., Marschik, R., Sutherland, P.B., Green, D., Sigafoos, V.A., Using, J.: iPods and iPads in teaching programs for individuals with developmental disabilities: A systematic review. Research in Developmental Disabilities 34, 147-156 (2013)

7. Lancioni, G.E., O'Reilly, M.F., Singh, N.N., Sigafoos, J., Oliva, D., Antonucci, M., Tota, A., Basili, G.: Microswitch-based programs for persons with multiple disabilities: an overview of some recent developments. Perceptual and Motor Skills 106, 355-370 (2008)

8. Lancioni, G.E., O’Reilly, M.F., Singh, N.N., Oliva, D., Coppa, M.M., Montironi, G.: A new microswitch to enable a boy with minimal motor behaviour to control environmental stimulation with eye blinks. Behavioral Interventions 20, 147-153 (2005)

9. Lancioni, G.E., O’Reilly, M.F., Oliva, D., Coppa, M.M.: A microswitch for vocalization responses to foster environmental control in children with multiple disabilities. Journal of Intellectual Disability Research 45(3), 271-275 (2001)

10. Brooks, A.L.: Soundscapes: the evolution of a concept, apparatus and method where ludic engagement in virtual interactive space is a supplemental tool for therapeutic motivation. PhD thesis (2011), http://vbn.aau.dk/files/55871718/PhD.pdf

11. Welton. T., Brown, D.J., Evett, L., Sherkat, N. A Brain-Computer Interface for the Dasher Alternative Text Entry System. Special Issue of Journal of Universal Access in the Information Society: 3rd generation accessibility: Information and Communication Technologies towards universal access (In press)

12. Barker, B.S., Ansorge, J.: Robotics as means to increase achievement scores in an informal learning environment. Journal of Research on Technology in Education 39(3), 229 (2007)

13. Johnson, J.: Children, robotics, and education. Artificial Life and Robotics 7(1-2), 16-21 (2003)

14. Salter, T., Werry, I., Michaud, F.: Going into the wild in child-robot interaction studies: issues in social robotic development. Intelligent Service Robotics 1(2), 93-108 (2008)

15. Robins, B., Dautenhahn, K., te Boekhorst, R., Billard, A.: Robotic Assistants in Therapy and Education of Children with Autism: Can a Small Humanoid Robot Help Encourage Social Interaction Skills? Universal Access in the Information Society 4(2), 105-120 (2005)

16. Klein, T., Gelderblom, G.J., de Witte, L., Vanstipelen, S.: Evaluation of short term effects of the IROMEC robotic toy for children with developmental disabilities. Paper presented at the IEEE International Conference on Rehabilitation Robotics, ICORR (2011), http://ieeexplore.ieee.org/xpls/abs all.jsp?arnumber $=5975406$ \&tag=1 (retrieved February 5, 2014) 
17. Ibrani, L., Allen, T., Brown, D., Sherkat, N., Stewart, D.: Supporting Students with Learning and Physical Disabilities using a Mobile Robot Platform. Paper presented at the Interactive Technologies and Games (ITAG), Nottingham, UK (2011),

http://itag.gamecity.org/proceedings/2011-2/

18. Hedgecock, J.: Can working with a robot enhance learning in pupils with intellectual disabilities? B Med. Sci. Dissertation submitted to the University of Nottingham (2013)

19. Department for Education (2012), http://www.education.gov.uk/schools/teachingandlearning/ assessment/a00203453/about-the-p-scales (accessed January 29, 2014)

20. Aldebaran Robotics. Solutions for Autism, Paris, France: Aldebaran Robotics (2006), http://www.aldebaran-robotics.com/en/Solutions/ ForAutism/NAO.html (accessed January 11, 2013)

21. The Special Schools and Academies Trust. The Complex Learning Difficulties and Disabilities Research Project: Developing Meaningful Pathways to Personalised Learning. Executive Summary. London: Schools Network (2011),

http://www.ssatrust.org.uk (retrieved February 6, 2014) 